\title{
Posterior atlantoaxial dislocation without fracture and neurologic deficit: a case report and the review of literature
}

\author{
Lei-Sheng Jiang · Lei Shen · Wei Wang • \\ Hao Wu $\cdot$ Li-Yang Dai
}

Received: 9 April 2009/Revised: 17 June 2009/Accepted: 16 August 2009/Published online: 28 August 2009

(C) Springer-Verlag 2009

\begin{abstract}
Traumatic posterior atlantoaxial dislocation without related fracture of the odontoid process is very rare, and only ten cases have been previously reported. The objective of this paper was to describe a case of traumatic posterior atlantoaxial dislocation without related fracture of the odontoid process, and its management with atlantoaxial transarticular screw fixation and bony fusion through an anterior retropharyngeal approach, and to review the relevant literature. The patient's medical and radiographic history is reviewed as well as the relevant medical literature. Posterior atlantoaxial dislocation was confirmed in a 48-year-old male struck by an automobile through conventional radiography, computed tomography and magnetic resonance imaging. No related fracture of the odontoid process or neurological deficit was found in this patient. Transarticular screw fixation of the atlantoaxial articulation through anterior retropharyngeal approach was performed after several unsuccessful attempts of closed reduction. At the latest follow-up, the lateral cervical spine radiography in flexion and extension demonstrated no instability of the atlantoaxial complex 21 months after the operation. In conclusion, patients with posterior
\end{abstract}

L.-S. Jiang · L. Shen · W. Wang · L.-Y. Dai

Department of Orthopaedic Surgery, Xinhua Hospital,

Shanghai Jiaotong University School of Medicine,

Shanghai, China

H. Wu

Department of Otolaryngology—Head and Neck Surgery,

Xinhua Hospital, Shanghai Jiaotong University School

of Medicine, Shanghai, China

L.-Y. Dai $(\bowtie)$

Xinhua Hospital, 1665 Kongjiang Road,

Shanghai 200092, China

e-mail: chinaspine@163.com atlantoaxial dislocation without fracture may survive with few or no-long term neurological deficit. Routine CT and MRI of the cervical spine should be carried out in patients with head or neck trauma to prevent missing of this rare clinical entity. Transarticular screw fixation of the atlantoaxial articulation through anterior retropharyngeal approach is safe and useful in case the management of dislocation is unsuccessful under closed reduction.

Keywords Atlantoaxial dislocation - Anterior retropharyngeal approach - Transarticular screw . Neurological deficit

\section{Introduction}

Although postmortem radiology of head and neck injuries in fatal traffic accidents detected quite a high percentage of atlantoaxial dislocations, either with or without odontoid fracture [1], only ten cases of traumatic posterior atlantoaxial dislocation without odontoid fracture in which the patients had been survived were reported in the English literature $[3,6-8,11,12,16,18,19]$. All the ten cases had no or mild neurological deficit, most of the dislocations were conservatively reduced with traction, and some of them were supplemented with internal fixation and fusion through posterior approach. We present here the eleventh case of a posterior atlantoaxial dislocation without odontoid fracture or neurological deficit. In addition to the excellent visualization of this rare trauma entity via magnetic resonance imaging (MRI), computed tomography (CT) with multiplanar reconstruction (MPR) and threedimensional reconstruction, the management of open reduction with partial excision of the odontoid process, atlantoaxial transarticular screw fixation and bony fusion 
through an anterior retropharyngeal approach also differs this case from the others. The patient was informed that data concerning the case would be submitted for publication.

\section{Case report}

A 48-year-old male patient, who was struck by an automobile on 6 December 2006, was transferred from a local county clinic to our university hospital 1 day after the traffic accident. According to the medical record of the county clinic, the patient had been unconscious for a short time but was alert and oriented on arrival at the clinic. $\mathrm{He}$ complained of considerable pain and stiffness in the neck, but the subsequent plain radiography was not clear enough to demonstrate any problem of the cervical spine. Although there were no evidence of concomitant chest or abdominal injuries, and no apparent deficit of the spinal cord or cranial nerves, the patient with normal vital signs was suspected of traumatic abnormalities of the head and neck, immobilized in a neck collar, and transferred for further diagnosis and treatment.

Physical examination on arrival at our hospital revealed extensive lacerations of the chin, mouth and lips and obvious torticollis. The patient reported pain and tenderness in the neck. Motion of flexion/extension and rotation of the neck were limited. The vital parameters were again normal, and neurological examination also showed no apparent deficit of the spinal cord.

The patient was taken immediately to the radiological department, and computed tomography for the head, conventional radiography, computed tomography with multiplanar reconstruction and three-dimensional reconstruction, and MRI of the cervical spine were performed. Neither fractures of the cranial bone nor subarachnoid haemorrhage or haematoma inside the brain was found on the initial CT scan of the head. Lateral radiography of the cervical spine demonstrated a posterior dislocation of the atlas with respect to the axis (Fig. 1) with no evident sign of the fracture. Axial CT scans confirmed that the odontoid peg lied ventral to the anterior arch of the atlas (Fig. 2a), while sagittal reconstructions (Fig. 2b) and three-dimensional reconstructions (Fig. 2c) verified not any fractures of the odontoid. MRI showed no cord compression or intramedullary cord signal abnormality at the level of the atlantoaxial dislocation (Fig. 3).

After confirmation of the diagnosis, the patient was directly sent into the operation room. Several times of closed reduction were attempted through gradual manual cranial traction under general anesthesia with fiberoptic nasotracheal intubation and fluoroscopic control, but failed. Open reduction was conducted right afterwards. The axis

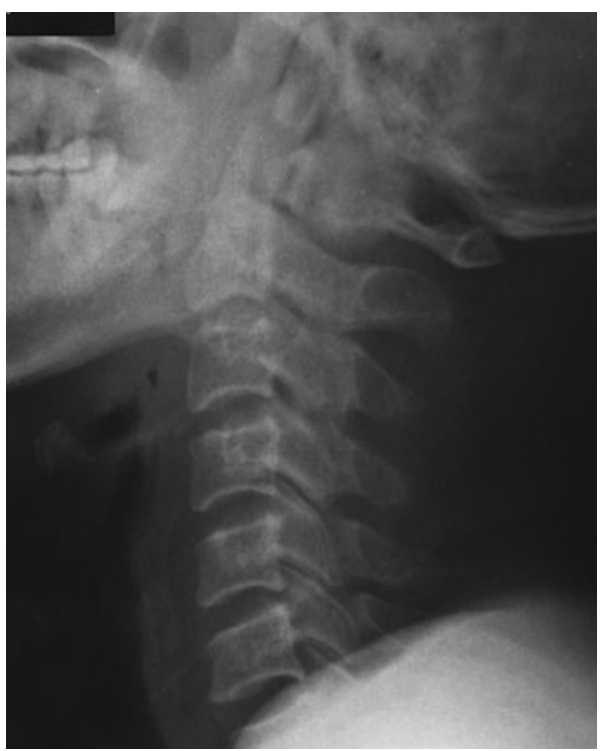

Fig. 1 Lateral radiography of the cervical spine demonstrated a posterior dislocation of the atlas with respect to the axis

and atlas were exposed via an anterior retropharyngeal approach described by DeAndrade and MacNab [4]. Partial odontoidectomy was performed with an electrical burr, followed by reduction of the atlantoaxial dislocation through gentle traction and slight flexion of the head. The atlantoaxial articulations were removed of their articular cartilage with a curved curet, autografted with morselized iliac crest bone, and fixed with two cannulated lag screws under anteroposterior and lateral fluoroscopy. Spinal cord monitoring was not available during the procedures.

The nasotracheal tube was removed immediately after the operation. The patient suffered from neurapraxia of the hypopharynx nerve and the superior laryngeal nerve, a complication of over-retraction during the exposure. This complication of neurapraxia resolved spontaneously within 1 month postoperatively. There were no iatrogenic neurological deficits of the spinal cord. No postoperative infection occurred in this patient. The patient was instructed to wear a Philadelphia collar for 3 months. At the latest follow-up, the flexion/extension lateral radiography of the cervical spine demonstrated no instability of the atlantoaxial complex 21 months after the operation (Fig. 4).

\section{Discussion}

The intrinsic stability of the atlantoaxial complex is mainly provided by the interlocking articular processes and the odontoid process interlocking in an osteo-ligamentous ring formed ventrally by the anterior arch of the atlas and dorsally by the transverse ligament. Most atlantoaxial dislocations are associated with odontoid fracture or 
Fig. 2 Axial CT scans

confirmed that the odontoid peg lied ventral to the anterior arch of the atlas (a), while sagittal reconstructions (b) and $3 \mathrm{D}$ reconstructions (c) verified not any fractures of the odontoid
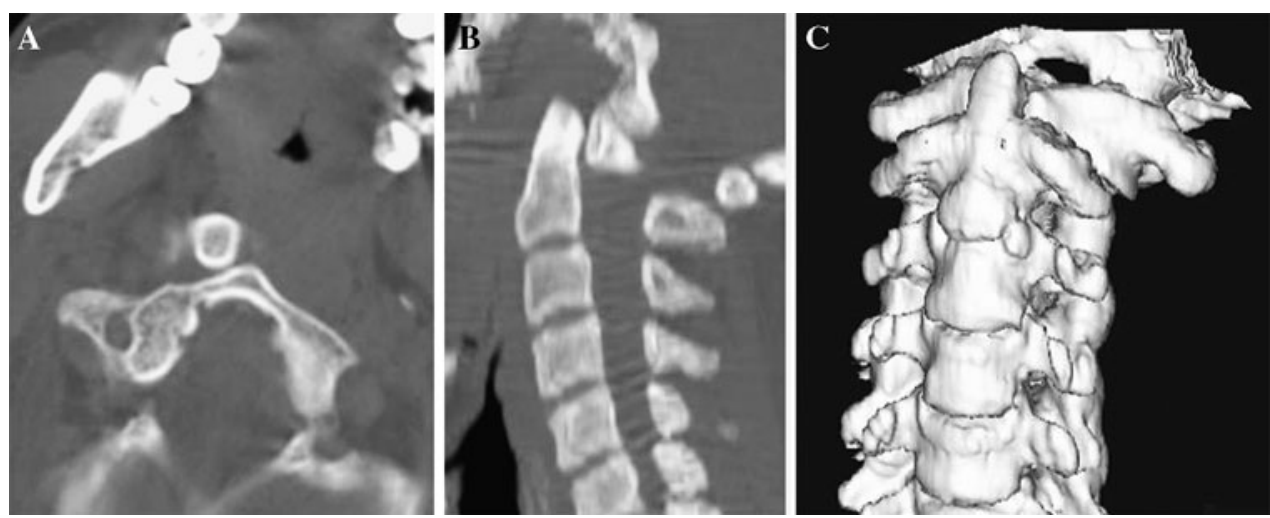

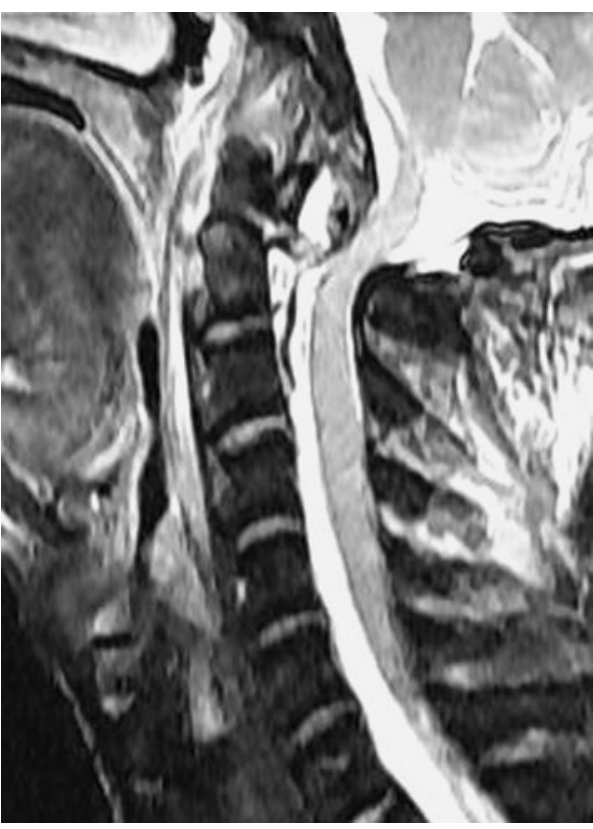

Fig. 3 MRI showed no cord compression or intramedullary cord signal abnormality at the level of the atlantoaxial dislocation rupture of the transverse atlantal ligament, and these dislocations are usually anterior owing to relatively weak ligamentous structure of the dorsal part of the ring. Till now, only ten cases of traumatic posterior atlantoaxial dislocation without odontoid fracture in which the patients had been survived were reported in the English literature [3, 6-8, 11, 12, 16, 18, 19]. However, it also seems likely that trauma sufficient to produce such a posterior dislocation would tend to cause enough displacement leading to major cord damage with immediate death. In this event, a lesion at this level might well be missed in a routine postmortem examination. The incidence of posterior atlantoaxial dislocation without odontoid fracture may therefore be much higher than recognized.

Hyperextension with variable amounts of distraction was proposed as the probable mechanism of posterior dislocation without a fracture of the odontoid by Haralson and Boyd [7]. Although not provable clinically or experimentally, this assumption has been well acknowledged among most of the authors and is strongly supported by the fact that seven of the ten reported cases have associated
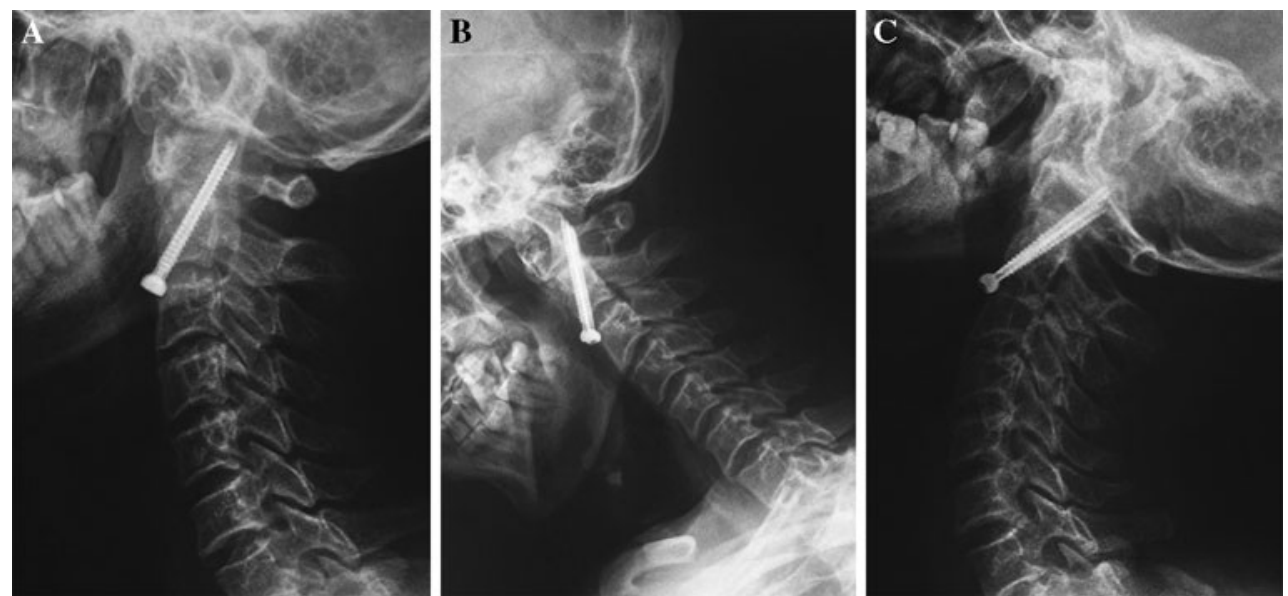

Fig. 4 Lateral cervical spine radiography in neutral (a), flexion (b) and extension (c) demonstrated no instability of the atlantoaxial complex 18 months after the operation 
facial or neck lacerations which were characteristics of hyperextension injury of the cervical spine (Table 1).

In the previously reported ten cases, none had any definite clinical symptoms or signs of neurological deficit pertaining to $\mathrm{C} 1-\mathrm{C} 2$ dislocation (Table 1). It seems that if posterior atlantoaxial dislocation without odontoid fracture does not lead to immediate death, it will not cause damage to the spinal cord at this level. This can be explained by Steel's Rule of Thirds [15]: one-third of the neural canal at the atlantoaxial level is occupied by the odontoid process, one-third by the cord, and one-third by the spinal fluid. In these patients, the injuring force was sufficient to produce only the amount of displacement visualized roentgenographically, and that sufficient ligamentous and soft-tissue attachments remained intact to lock the axis in the displaced position. So, enough space was present posteriorly for the spinal cord and it therefore was not compressed. Furthermore, Tucker and Taylor [17] in a skeletal study of spinal canal capacity in simulated displacements of the atlantoaxial segment has demonstrated that posterior dislocation without fracture of the odontoid reduced the canal area to $36 \%$, which is sufficient to avoid cord compromise.

Not rarely, plain radiography of the cervical spine does not show the atlas and axis clearly, either due to overlap of the cranial bones or due to some compulsive positions of the head or neck of the patients. So, in the emergency care unit, atlantoaxial dislocation is not infrequently missed under routine anteroposterior and lateral radiography of the cervical spine unless it is suspected and kept in mind, and further examinations such as tomography and open-mouth view are taken. With the advent of CT scan technique, bony structures of the $\mathrm{C} 1-\mathrm{C} 2$ complex are clearly demonstrated. In our case, axial CT scans provided illustrative images that the odontoid peg lied ventral to the anterior arch of the atlas, while sagittal reconstructions and threedimensional reconstructions verified not any fractures of the odontoid. With the characteristic of high resolution for soft tissues, MRI of the cervical spine for our patient showed the tortuous course taken by the spinal cord, but no cord compression or intramedullary cord signal abnormality at the level of the atlantoaxial dislocation. Therefore, we recommend the use of CT and/or MRI of the cervical spine in selected patients with head or neck trauma suspected of atlantoaxial dislocation.

As for the treatment of posterior atlantoaxial dislocation, most of the reported cases were successfully managed with closed reduction through gradual manual traction or skeletal cervical traction (Table 1). This seemingly simple procedure actually is very dangerous and highly technically demanding for several reasons. First, it is very difficult to determine how much force applied is appropriate and overdistraction of the $\mathrm{C} 1-\mathrm{C} 2$ complex can lead to immediate

Table 1 Summary of the previously published ten cases

\begin{tabular}{|c|c|c|c|c|c|c|c|}
\hline \multirow{2}{*}{$\begin{array}{l}\text { Case } \\
\text { no. }\end{array}$} & \multirow[t]{2}{*}{ References } & \multirow{2}{*}{$\begin{array}{l}\text { Age, } \\
\text { Sex }\end{array}$} & \multirow[t]{2}{*}{ Facial lacerations } & \multirow[t]{2}{*}{ Neurodeficit } & \multicolumn{2}{|l|}{ Reduction } & \multirow{2}{*}{$\begin{array}{l}\text { Operation } \\
\text { and approach }\end{array}$} \\
\hline & & & & & Closed & Open & \\
\hline 1 & Haralson [7] & $30, \mathrm{M}$ & Yes & No & Yes & No & $\begin{array}{l}\text { Posterior wiring and } \\
\text { fusion }\end{array}$ \\
\hline 2 & Sassard [12] & $20, \mathrm{~F}$ & Yes & $\begin{array}{l}\text { No on initial } \\
\text { examination }\end{array}$ & Yes & No & No \\
\hline 3 & Patzakis [11] & $37, \mathrm{M}$ & Yes & No & Yes & No & No \\
\hline 4 & Fox [6] & $65, \mathrm{M}$ & Not mentioned & $\begin{array}{l}\text { Transient quadriplegia, } \\
\text { recovered } 5 \mathrm{~h} \text { after the } \\
\text { injury }\end{array}$ & No & Yes & $\begin{array}{l}\text { Anterior transoral } \\
\text { odontoidectomy and } \\
\text { posterior wiring and } \\
\text { cement stabilization }\end{array}$ \\
\hline 5 & Jamshidi [8] & $22, \mathrm{M}$ & Yes & No & Yes & No & $\begin{array}{l}\text { Posterior wiring and } \\
\text { fusion }\end{array}$ \\
\hline 6 & Wong [18] & $23, \mathrm{M}$ & Not mentioned & $\begin{array}{l}\text { Abnomal sensation from } \\
\text { T7-8 level }\end{array}$ & Yes & No & $\begin{array}{l}\text { Posterior wiring and } \\
\text { fusion }\end{array}$ \\
\hline 7 & Sud [16] & $38, \mathrm{M}$ & Not mentioned & $\begin{array}{l}\text { Upper limb weakness } \\
\text { secondary to brachial } \\
\text { plexus injury }\end{array}$ & $\begin{array}{l}\text { Yes but failed due to } \\
\text { quadriparesis during } \\
\text { traction }\end{array}$ & Yes & $\begin{array}{l}\text { Partial odontoidectomy } \\
\text { and posterior fixation }\end{array}$ \\
\hline 8 & Yoon [19] & $22, \mathrm{M}$ & Yes & $\begin{array}{l}\text { Possibly due to } \\
\text { subarachnoid } \\
\text { hemorrhage }\end{array}$ & No & Yes & $\begin{array}{l}\text { Posterior transarticular } \\
\text { screw fixation }\end{array}$ \\
\hline 9 & Neumann [10] & $64, \mathrm{M}$ & Yes & No & Yes & No & No \\
\hline 10 & Chaudhary [3] & $35, \mathrm{~F}$ & $\begin{array}{l}\text { Over the nape } \\
\text { of the neck }\end{array}$ & $\begin{array}{l}\text { Corresponded to the } \\
\text { C6-C7 facetal } \\
\text { subluxation }\end{array}$ & Yes & No & No \\
\hline
\end{tabular}


death of the patient $[2,13]$. For fear of this lethal complication of closed reduction, Yoon et al. [19] adopted an operation-assisted reduction in their case to avoid overdistraction of the spinal cord. Second, the traction procedure must be done under repeated fluoroscopic control and continuous neurological monitoring which are not always available at hand. Third, proper rotation and flexion/ extension maneuver of the patient's head must be incorporated into the traction process to make the odontoid process slip back into the osteo-ligamentous ring of the atlas, and this maneuver also has a great potential to injure the spinal cord. As described by Wong et al. [18], he carried out the reduction in three phases. Distraction phase: traction applied in slight flexion to keep C1 ring apposed to posterior odontoid. Realignment phase: $\mathrm{C} 1$ ring has slipped back over the odontoid but is displaced too far forward because of slightly excessive flexion angle of traction. Release phase: traction changed to slight extension, allowing $\mathrm{C} 1$ ring to come closer to anterior odontoid. Traction was then released over several hours. This threephase closed reduction technique is also very challenging.

In terms of stability after reduction of posterior atlantoaxial dislocation, most authors of previous studies believed that the transverse ligament was intact or not severely damaged, and a spared transverse ligament probably provided the atlantoaxial complex with sufficient stability following reduction of the odontoid peg into the osteo-ligamentous ring. In fact, four patients who were managed with closed reduction achieved stability without fusion or internal fixation [3,10-12]. Although the integrity of the transverse ligament was investigated in the case of Chaudhary et al. [3] using MRI technique of and an intact transverse ligament was even confirmed, the other six cases were all supplemented with posterior fusion and internal fixation for fear of residual instability or incomplete reduction (Table 1).

In our case, we tried to reduce the posterior atlantoaxial dislocation through gradual manual traction at first. Although the traction procedure was done under fluoroscopic control, we were not confident at the appropriate traction force and worried about the lethal complication of overdistraction of the spinal cord. After two times of unsuccessful attempts, we proceeded to direct open reduction and transarticular screw fixation through an anterior retropharyngeal approach. In most circumstances, the posterior approach is preferred for the stabilization of atlantoaxial instability due to the ease of dissection, the relatively low incidence of complications, the high success rate of fusion, and familiarity to most surgeons. It was perhaps these advantages that prompted the authors of the previous reports to adopt the posterior approach in all their operated cases (Table 1). The anterior retropharyngeal approach is a cranial extension through the same fascial planes as the anterior cervical approach described by Southwick and Robinson [14] for exposure of C3 through T1. This allowed sufficient exposure to perform a bilateral anterior transarticular screw fixation of the atlas and the axis, and the anatomic feasibility of this technique had been well demonstrated in the experiment of CT based morphometric measurements of axis and atlas vertebra in 42 healthy patients by Koller et al. [9] The anterior retropharyngeal approach avoids the inconvenience of changing the patient from supine position necessary for intubation anaesthesia to prone position for posterior approach, potentially decreases the infection rate of transoral approach [5], and most importantly, obviates inappropriate manipulation of the head and neck which can lead to catastrophic complications after posterior atlantoaxial dislocation.

Conflict of interest statement None of the authors has any potential conflict of interest.

\section{References}

1. Alker GJ, Oh YS, Leslie EV, Panaro VA, Eschner EG (1975) Postmortem radiology of head and neck injuries in fatal traffic accidents. Radiology 114:611-617

2. Botelho RV, de Souza Palma AM, Abgussen CM, Fontoura EA (2000) Traumatic vertical atlantoaxial instability: the risk associated with skull traction. Case report and literature review. Eur Spine J 9:430-433

3. Chaudhary R, Chaudhary K, Metkar U, Rathod A, Raut A, Sanghvi D (2008) Posterior atlantoaxial dislocation without odontoid fracture. Skeletal Radiol 37:361-366

4. DeAndrade JR, MacNab I (1969) Anterior occipito-cervical fusion using an extra-pharyngeal exposure. J Bone Joint Surg Am 51:1621-1626

5. Fang HSY, Ong GB (1962) Direct anterior approach to the upper cervical spine. J Bone Joint Surg Am 44:1588-1604

6. Fox JL, Jerez A (1977) An unusual atlanto-axial dislocation. Case report. J Neurosurg 47:115-118

7. Haralson RH III, Boyd HB (1969) Posterior dislocation of the atlas on the axis without fracture. Report of a case. J Bone Joint Surg Am 51:561-566

8. Jamshidi S, Dennis MW, Azzam C, Karim N (1983) Traumatic posterior atlantoaxial dislocation without neurological deficit: case report. Neurosurgery 12:211-213

9. Koller H, Kammermeier V, Ulbricht D, Assuncao A, Karolus S, van den Berg B, Holz U (2006) Anterior retropharyngeal fixation C1-2 for stabilization of atlantoaxial instabilities: study of feasibility, technical description and preliminary results. Eur Spine J 15:1326-1338

10. Neumann U, Urbanski H, Riedel K (2003) Posterior atlantoaxial dislocation without fracture of the odontoid. A case report. J Bone Joint Surg Am 85:1343-1346

11. Patzakis MJ, Knopf A, Elfering M, Hoffer M, Harvey JP Jr (1974) Posterior dislocation of the atlas on the axis: a case report. J Bone Joint Surg Am 56:1260-1262

12. Sassard WR, Heinig CF, Pitts WR (1974) Posterior atlanto-axial dislocation without fracture. Case report with successful conservative treatment. J Bone Joint Surg Am 56:625-628

13. Silbergeld DL, Laohaprasit V, Grady MS, Anderson PA, Winn HR (1991) Two cases of fatal atlantoaxial distraction injury without fracture or rotation. Surg Neurol 35:54-56 
14. Southwick WO, Robinson RA (1957) Surgical approaches to the vertebral bodies in the cervical and lumbar regions. J Bone Joint Surg Am 39:631-644

15. Steel HH (1968) Anatomical and mechanical consideration of the atlantoaxial articulation. J Bone Joint Surg Am 50:1481-1482

16. Sud S, Chaturvedi S, Buxi TB, Singh S (2002) Posterior atlantoaxial dislocation without associated fracture. Skeletal Radiol $31: 529-531$
17. Tucker SK, Taylor BA (1998) Spinal canal capacity in simulated displacements of the atlantoaxial segment: a skeletal study. J Bone Joint Surg Br 80:1073-1078

18. Wong DA, Mack RP, Craigmile TK (1991) Traumatic atlantoaxial dislocation without fracture of the odontoid. Spine 16:587-589

19. Yoon DH, Yang KH, Kim KN, Oh SH (2003) Posterior atlantoaxial dislocation without fracture: case report. J Neurosurg 98:73-76 